\title{
Novel piezoelectric paper based on SbSI nanowires
}

\author{
Bartłomiej Toroń • Piotr Szperlich (i) - Marian Nowak • Danuta Stróż • \\ Tomasz Rzychoń
}

Received: 15 May 2017/Accepted: 27 November 2017/Published online: 4 December 2017

(C) The Author(s) 2017. This article is an open access publication

\begin{abstract}
A novel piezoelectric paper based on antimony sulfoiodide (SbSI) nanowires is reported. The composite of tough sonochemically produced SbSI nanowires (with lateral dimensions $10-100 \mathrm{~nm}$ and length up to several micrometers) with very flexible cellulose leads to applicable, elastic material suitable to use in fabrication of, for example, piezoelectric nanogenerators. For mechanical energy harvesting, cellulose/SbSI nanocomposite may be used. Due to its high values of electromechanical coefficient $\left(\mathrm{k}_{33}=0.9\right) \quad$ and piezoelectric coefficient $\left(\mathrm{d}_{33}=1 \times 10^{-9} \mathrm{C} / \mathrm{N}\right)$, SbSI is a very attractive material for such devices. The preliminary investigations of a simple cellulose/SbSI nanogenerator for shock pressure $(\mathrm{p}=3 \mathrm{MPa})$ and sound excitation ( $\mathrm{f}=175 \mathrm{~Hz}, \mathrm{~L}_{\mathrm{p}}=90 \mathrm{~dB}$ ) allowed to determine its open circuit voltage $2.5 \mathrm{~V}$ and $24 \mathrm{mV}$, respectively. For a load resistance equal to source impedance $\left(Z_{\mathrm{S}}=2.90(11) \mathrm{M} \Omega\right)$, maximum output power density
\end{abstract}

B. Toroń · P. Szperlich $(\varangle) \cdot$ M. Nowak

Institute of Physics, Center for Science and Education, Silesian University of Technology, Krasinskiego 8 St., 40-019 Katowice, Poland

e-mail: piotr.szperlich@polsl.pl

D. Stróż

Institute of Materials Science, University of Silesia, 75

Pułku Piechoty 1A St., 41-500 Chorzow, Poland

T. Rzychoń

Department of Materials Science, Silesian University of

Technology, Krasińskiego 8 St., 40-019 Katowice, Poland
$\left(\mathrm{P}_{\mathrm{L}}=41.5 \mathrm{nW} / \mathrm{cm}^{3}\right.$ for $0.05-\mathrm{mm}$-thick sheet of this composite) of the cellulose/SbSI nanogenerator was observed. Cellulose/SbSI piezoelectric paper may also be useful to construct gas nanosensors and actuators.

Keywords Piezoelectric paper - Antimony sulfoiodide $\cdot$ Nanowires $\cdot$ Piezoelectric semiconductors

\section{Introduction}

Currently, a great demand for energy harvesting is observed. The first piezoelectric nanogenerator (NG) based on zinc oxide nanowires for mechanical to electrical energy conversion was proposed by Wang and Song (2006). It started with promising investigations on such devices, for example, to harvest vibrations (Chen et al. 2010, 2013; Poulin-Vittrant et al. 2015; Zhan et al. 2014), human body motion (Lee et al. 2014; Yang et al. 2009), wind (Gao et al. 2015), acoustic waves (Wang et al. 2007), and other mechanical energy forms (Wang 2012). Piezoelectric generators are also used as passive or self-powered sensors (Chen et al. 2013; Fan et al. 2012; Fang et al. 2015; Hua and Wang 2015). Fabrication of a mechanically flexible, piezoelectric nanocomposite material consisting of zinc oxide ( $\mathrm{ZnO}$ ) nanostructures embedded in a stable matrix of cellulose fibers was presented by Gullapalli et al. (2010). They reported applicability 
of this piezoelectric paper as a strain sensor. Kumar et al. (2011) demonstrated that nanocomposite consisting of $\mathrm{ZnO}$ nanostructures embedded in a common paper matrix can be directly used as energy-conversion devices to transform mechanical energy to electric power (with output voltage and power up to $80 \mathrm{mV}$ and $50 \mathrm{nW} / \mathrm{cm}^{2}$, respectively). Mahadeva et al. (2014) developed hybrid piezoelectric paper through fiber functionalization that involves anchoring nanostructured barium titanate $\left(\mathrm{BaTiO}_{3}\right)$. This paper had the largest piezoelectric coefficient, $\mathrm{d}_{33}=4.8(4) \times 10^{-12} \mathrm{C} / \mathrm{N}$, at the highest nanoparticle loading of $48 \mathrm{wt} \% \mathrm{BaTiO}_{3}$. Paper-based piezoelectric generator made of bacterial cellulose and $\mathrm{BaTiO}_{3}$ was presented by Zhang et al. (2016).

Recently, antimony sulfoiodide (SbSI) nanowires have been applied for ferroelectric nanogenerator operating under shock pressure (Mistewicz et al. 2016). Also, electrospun polyacrylonitrite (PAN) fibers containing SbSI nanowires have been used to construct a simple PAN/SbSI piezoelectric generator (Nowak et al. 2017). The amplitude of the voltage pulse, generated under shock pressure of 3.0 MPa, has reached $180 \mathrm{~V}$ in this nanogenerator. The peak output voltage of about $0.2 \mathrm{~V}$ was measured in bending/ releasing conditions with the deformation frequency of $1 \mathrm{~Hz}$ (Nowak et al. 2017).

Due to its high values of electromechanical coefficient $\mathrm{k}_{33}=0.9$ (Hamano et al. 1965) and piezoelectric coefficient $\mathrm{d}_{33}=1 \times 10^{-9} \mathrm{C} / \mathrm{N}$ (Grekov et al. 1973), it should be underlined that SbSI is very attractive for piezoelectric generators. Textured polycrystalline SbSI was used for the construction of actuators (Nowak et al. 2009b). The Curie temperature of ferroelectric SbSI nanowires $\left[\mathrm{T}_{\mathrm{C}}=292(1) \mathrm{K}\right.$ (Szperlich et al. 2009)] is close to room temperature. But, the coexistence of ferroelectric and paraelectric phases is observed in SbSI crystals at rather wide range of temperatures, for example, $38 \mathrm{~K}$ (Zadorozhnaya et al. 1973). An increase in the Curie temperature to $338 \mathrm{~K}$ was reported for an ingot of the composition $\mathrm{SbS}_{0.8} \mathrm{O}_{0.2} \mathrm{I}$ (Nitsche et al. 1964).

In this paper, we present the fabrication of novel piezoelectric paper based on SbSI nanowires for the first time. Preliminary investigations of nanogenerators made of this material are also reported.

\section{Experiment}

Figure 1 summarizes the fabrication of cellulose/SbSI composite. At first, SbSI nanowires were sonochemically synthesized from pure elements (antimony, sulfur, and iodine). In a typical procedure, the stoichiometric mixture of elements (e.g., $0.250 \mathrm{~g} \mathrm{~S}$, $0.949 \mathrm{~g} \mathrm{Sb}$, and $0.990 \mathrm{~g} \mathrm{I}_{2}$ ) was placed in $4 \mathrm{ml}$ of ethanol in polypropylene container closed by polyethylene plug to avoid outflow of volatile synthesis products. The container was submerged in water in cup-horn of $750 \mathrm{~W}$ ultrasonic processor VCX-750 equipped with sealed converter VC-334 (Sonics \& Materials, Inc.). Ultrasound frequency was $20 \mathrm{kHz}$, and the power density guaranteed by the manufacturer was $565 \mathrm{~W} / \mathrm{cm}^{2}$. The water was kept at constant temperature $(293 \mathrm{~K})$ by refrigerated circulating bath AD07R (PolyScience). Using spectrophotometer PC2000 (Ocean Optics Inc.) equipped with the ISP-REF integrating sphere (Ocean Optics Inc.), the process was monitored ex situ by diffuse reflectance spectroscopy (DRS).

The synthesis was continued to obtain red-orange gel with absorption edge of SbSI clearly identified (Fig. 2a). The whole synthesis process was performed for $2 \mathrm{~h}$.

The gel was rinsed 10 times with pure ethanol to remove remaining substrate and centrifuged to extract the product using the MPW-223e centrifuge (MPW Med. Instruments). SbSI gel was dried under the pressure of $60 \mathrm{~Pa}$ at room temperature for $72 \mathrm{~h}$. The xerogel consisted of SbSI nanowires. Their sizes and structures were determined using a JEOL-JEM 3010 microscope, working at a $300 \mathrm{kV}$ accelerating voltage. Characterization of the SbSI gel was accomplished using other techniques, such as X-ray powder diffraction (XRD), scanning electron microscopy (SEM), energy-dispersive X-ray spectroscopy (EDS), and selected area electron diffraction (SAED). The equipment and procedures were the same as presented by Nowak et al. (2008, 2014).

Cellulose fibers, from International Paper Co. (Kwidzyn), with lateral dimensions of 10-25 $\mu \mathrm{m}$ and length up to a few millimeters were sonically dispersed in water. In the next step, SbSI xerogel was added to them in the mass ratio 1:4. Ultrasound irradiation was used again for $2 \mathrm{~h}$ to ensure homogeneous mixture of cellulose fibers and SbSI nanowires. The dilute suspension of cellulose fibers/SbSI 


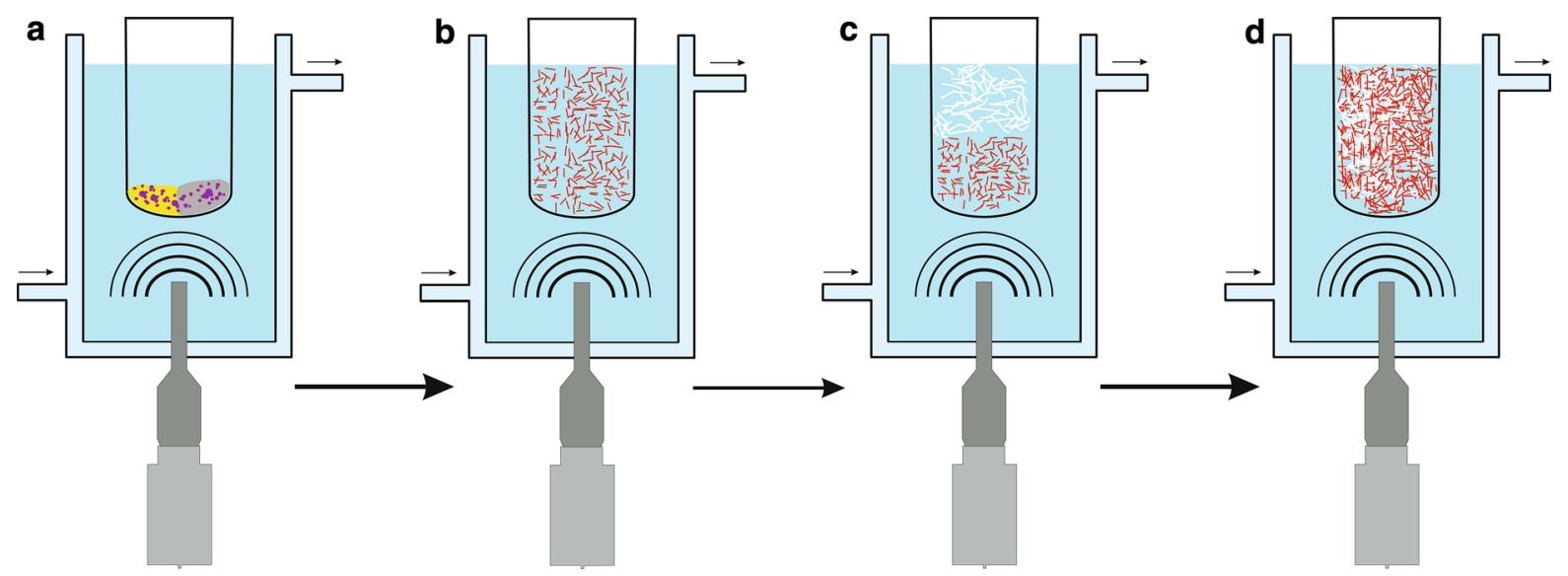

Fig. 1 Scheme of sonochemical preparation of cellulose/SbSI nanocomposite: a initial elements (sulfur, antimony, and iodine) were sonicated in ampoule filled with ethanol; b SbSI nanowires were obtained after $2 \mathrm{~h}$ of sonication; c cellulose fibers and SbSI

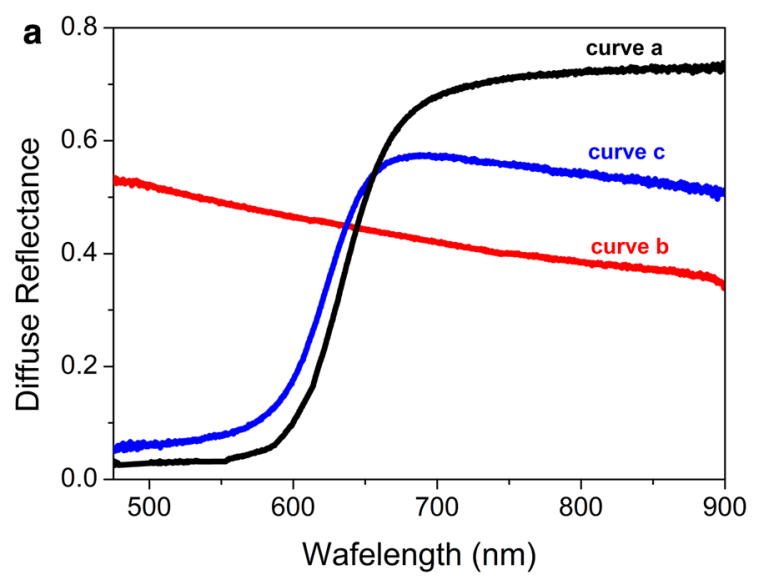

nanowires (10 times rinsed in ethanol) were sonicated together in water; d homogenous mixture of cellulose and SbSI nanowires were obtained after $2 \mathrm{~h}$

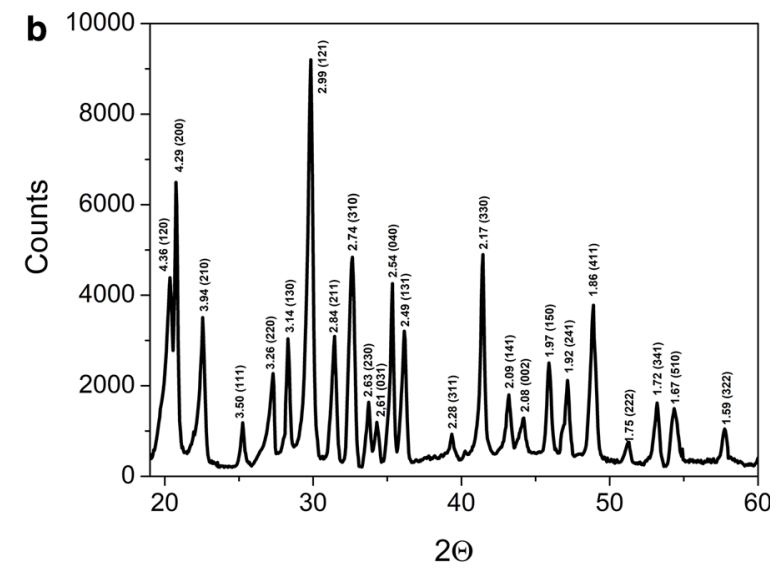

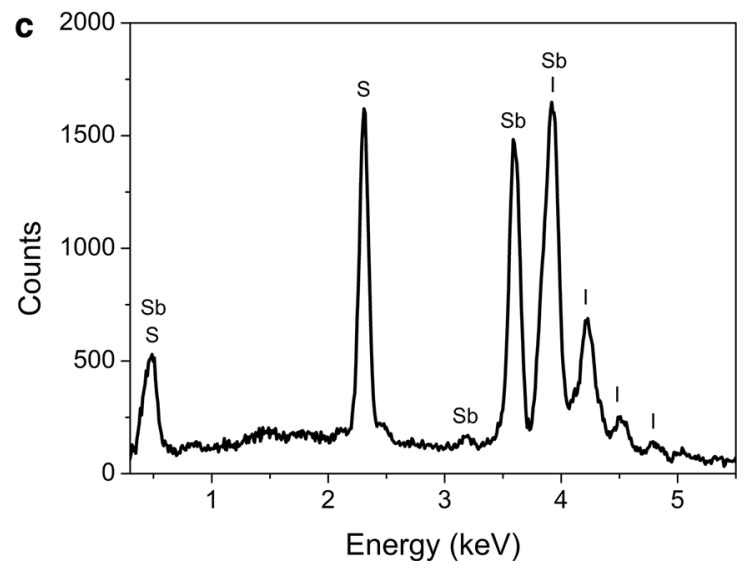

Fig. 2 a Diffuse reflectance of sonochemically produced SbSI sol (curve a), cellulose (curve b), and cellulose/SbSI composite (curve c); $\mathbf{b}$ the powder XRD pattern of SbSI nanowires; $\mathbf{c}$ EDS spectrum of sonochemically prepared SbSI nanowires 
nanowires was deposited on blotting paper and pressed to make sheets of cellulose/SbSI nanocomposite (cellulose/SbSI NC). Typical thickness of these sheets was $0.05 \mathrm{~mm}$. Phenom PRO $\mathrm{X}$ scanning electron microscope (Phenom World) equipped with EDS detector was used to study the morphology and chemical composition of the products.

The prepared cellulose/SbSI NC sheets (Fig. 3a) were used as active layers in fabricated nanogenerators. First, the $10 \times 10 \mathrm{~mm}^{2}$ sample was cut from cellulose/SbSI NC (Fig. 3b). Thin-film gold electrodes (Fig. 3c) were deposited on both sides of it using sputter coater Q150T ES (Quorum). Cooper wires were connected to gold electrodes (Fig. 3d) using high-purity silver paste 05002-AB (SPI Supplies). Such prepared sample was coated with Elastosil N10 silicones rubber (DRAWIN Vertriebs-GmbH) to protect it from the influence of ambient moisture and mechanical failure (Fig. 3e). Figure $3 \mathrm{f}$ presents the photograph of fabricated cellulose/SbSI nanogenerator. Capacity $86 \mathrm{pF}$ and tan Delta equal 0.05 were measured for $\mathrm{f}=1 \mathrm{kHz}$ using impedance analyzer 3532-50 LCR HITESTER (Hioki).

Functional parameters (generated voltage, current, and power) of cellulose/SbSI nanogenerators were measured at room temperature in ambient atmosphere.
Acoustic waves were generated by a loudspeaker biased with function generator MXG-9802 (METEX). Samples were located on testing table while the loudspeaker was placed slightly over them to avoid influence of housing vibration on response characteristics. Using T-01 sound level meter (Sonopan), the sound pressure level was measured. To examine cellulose/SbSI NGs response on shock pressure, Zoraki HP-01 air gun (Atak Arms CO., LTD) was used. The air shock waves with approximately $144 \mathrm{~m} /$ s velocity and pressure of $3 \mathrm{MPa}$ were pointed onto SbSI nanodevices. Shock pressure was measured with S-10 pressure sensor (WIKA Alexander Wiegand SE \& Co. KG). Using DS 1202CA digital oscilloscope (Rigol) and EG\&G 5110 dual phase lock in amplifier (Princeton Applied Research), open circuit voltages generated in cellulose/SbSI NGs were recorded. Measurements of U-I characteristics for different load resistances were performed using Zeal decade resistance box ( $1 \Omega-1 \mathrm{G} \Omega$ ). LabView program was developed for computer controlling the experiment, data acquisition and analysis.
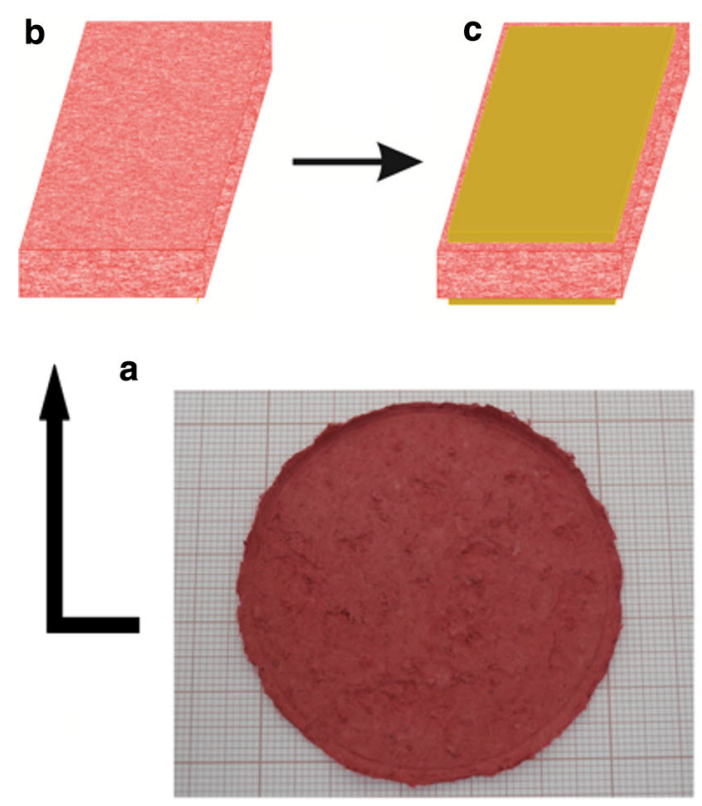

Fig. 3 Scheme of cellulose/SbSI nanogenerator assembly steps: a photo of cellulose/SbSI sheet; b sample cut from this sheet; c gold electrodes deposited on both sides of cellulose/

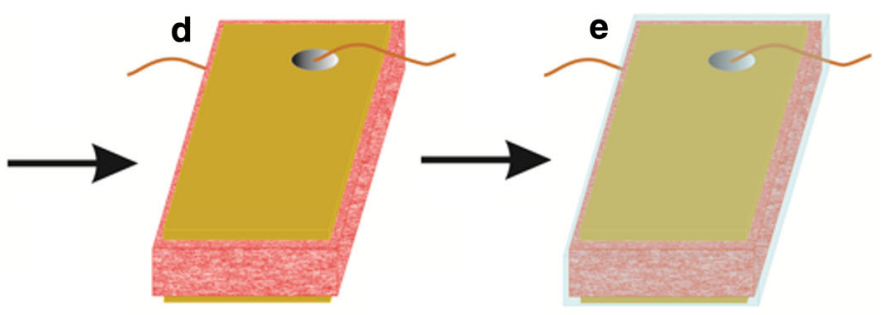

$\mathbf{f}$

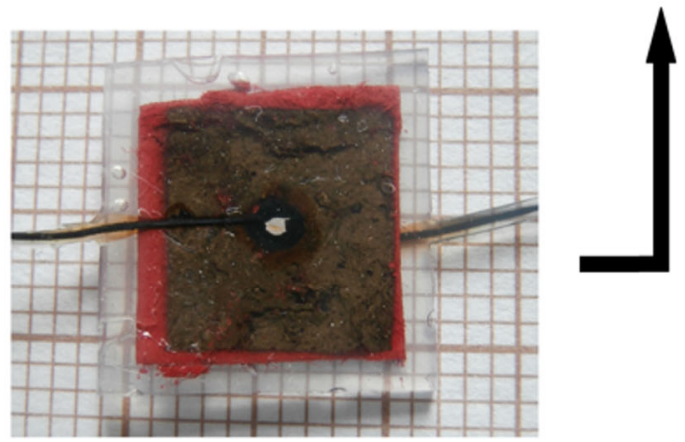

SbSI sheet; $\mathbf{d}$ wires mounted by silver paste to the electrodes; e device coated with protective layer of silicones rubber; $\mathbf{f}$ photo of piezoelectric cellulose/SbSI nanogenerator 


\section{Results and discussion}

Figures 2b, c and 4a, respectively, present XRD, EDS, and SEM results. The powder XRD pattern shows well-defined peaks. It indicates that obtained product has high purity and is well crystallized. No peaks of any other phases are detected. All the diffraction peaks can be indexed to be a pure orthorhombic phase for SbSI with the cell constants such as a $=0.858 \mathrm{~nm}$, $\mathrm{b}=1.017 \mathrm{~nm}$, and $\mathrm{c}=0.414 \mathrm{~nm}$. The identification was performed using the PCSIWIN computer program and the data from Antimony Sulfide Iodide (2000).

The product consisted of needle-shaped nanowires with lateral dimensions in the range from 10 to $50 \mathrm{~nm}$,

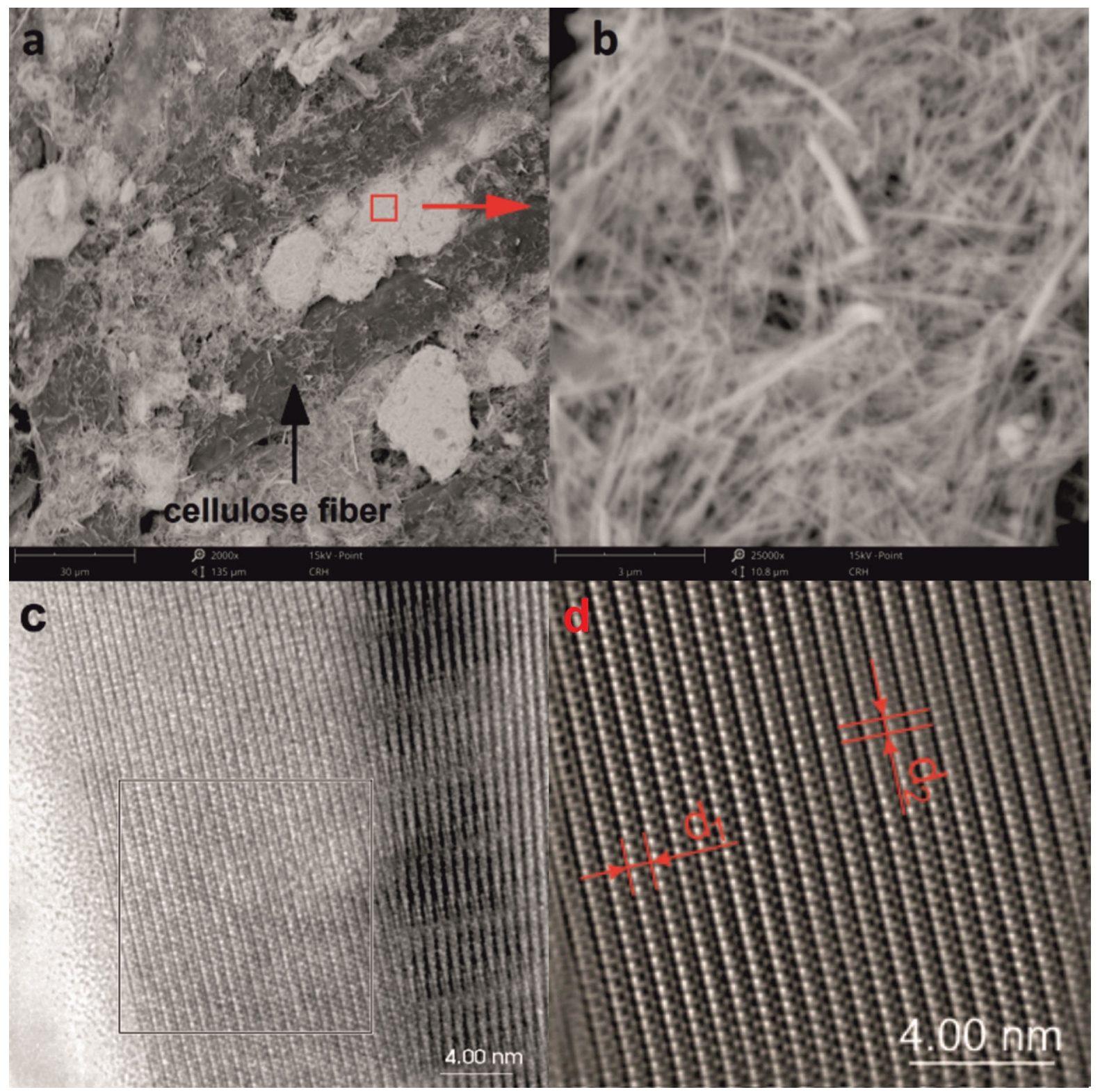

Fig. 4 a SEM micrograph of cellulose/SbSI nanocomposite; b magnification of SbSI nanowires filling free space among cellulose fibers; c HRTEM micrograph of SbSI nanowires showing clear Moir' fringes; d fast Fourier transform (FFT) image of single SbSI nanowire marked in (c). The fringe spacings of $\mathrm{d}_{1}=0.649(6) \mathrm{nm}$ and $\mathrm{d}_{2}=0.415(5) \mathrm{nm}$ correspond to the interplanar distances of $0.64989 \mathrm{~nm}$ and $0.4160 \mathrm{~nm}$ between the (110) and (001) planes of SbSI crystal (Antimony Sulfide Iodide 2000), respectively 

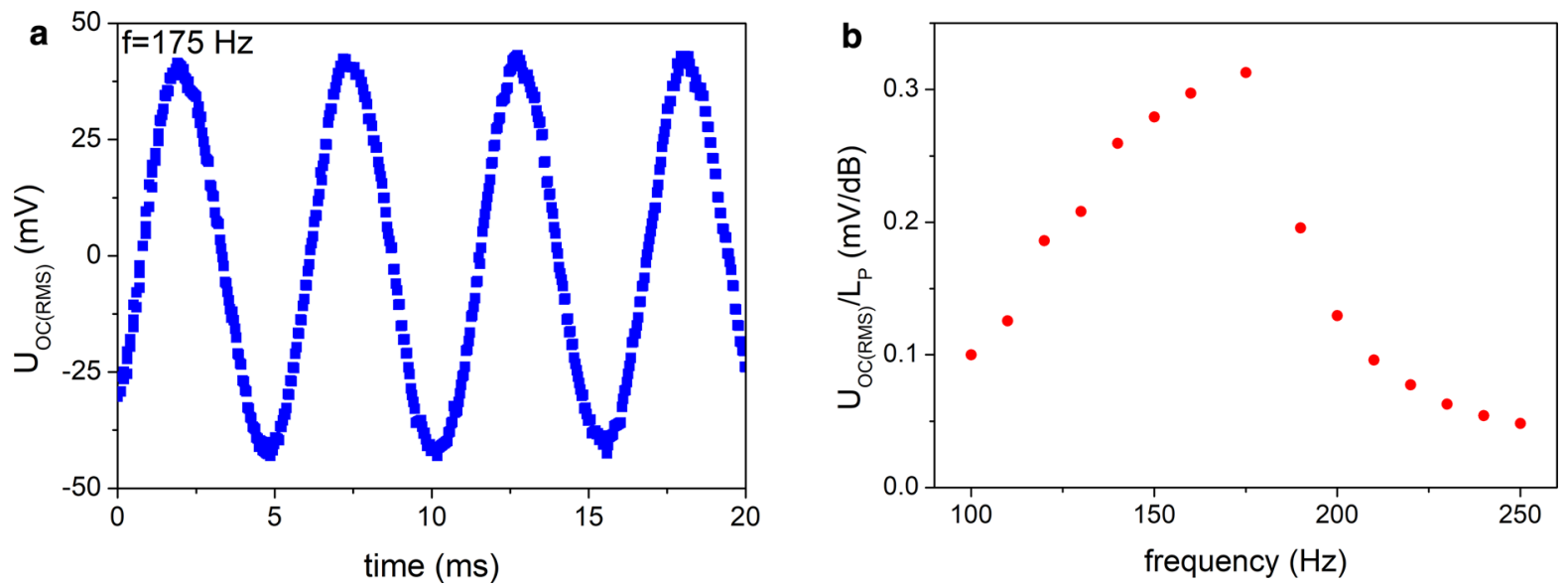

Fig. 5 a Open circuit response of cellulose/SbSI nanogenerator for sound excitation $\left(f=175 \mathrm{~Hz}, \mathrm{~L}_{\mathrm{p}}=90 \mathrm{~dB}\right.$ ). b Normalized frequency spectrum of $\mathrm{U}_{\mathrm{OC}(\mathrm{RMS})}$ response of cellulose/SbSI nanogenerator

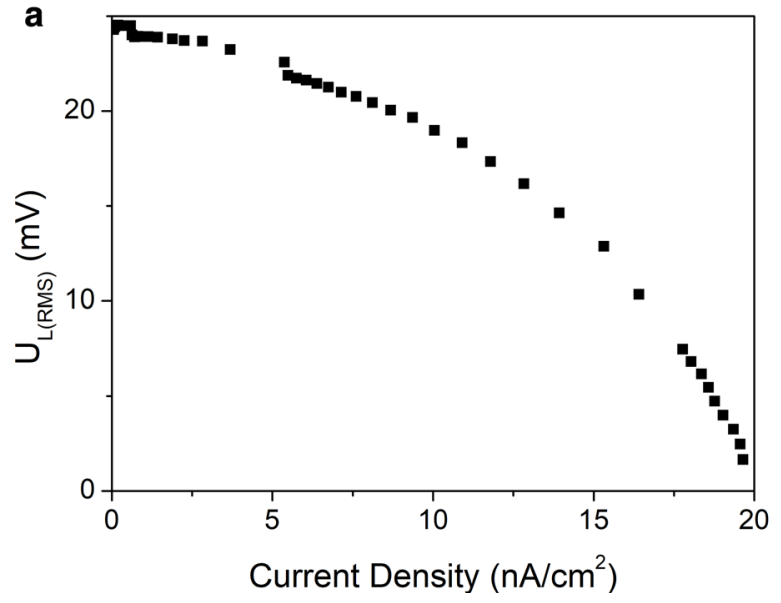

Fig. 6 a Output voltage of cellulose/SbSI nanogenerator vs current density calculated for electrode area. b Power density calculated for volume of cellulose/SbSI vs load resistance for

and the lengths up to several micrometers. The EDS spectrum (Fig. 2c) performed on these nanowires shows peaks for antimony, sulfur, and iodide only and confirms an elemental atomic ratio of 0.33:0.33:0.34 for sulfur, iodine, and antimony, respectively. It indicates a stoichiometric SbSI within the experimental error.

The HRTEM micrograph of a single SbSI nanowire (Fig. 4c, d) exhibited clear lattice fringes parallel to the nanowire axis. The fringe spacing of $\mathrm{d}_{1}=0.649(6) \mathrm{nm}$ and $\mathrm{d}_{2}=0.415(5) \mathrm{nm}$ corresponded to the interplanar distances of 0.64989 and $0.4160 \mathrm{~nm}$ between the (110) and (001) planes of

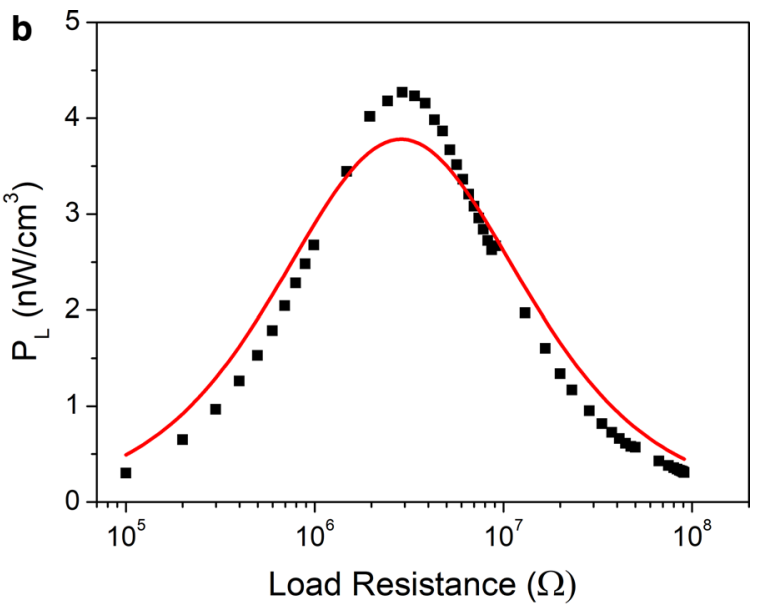

sound excitation ( $\mathrm{f}=175 \mathrm{~Hz}, \mathrm{~L}_{\mathrm{p}}=90 \mathrm{~dB}$ ). Red curve presents fitted theoretical dependence. Description in the text

orthorhombic structure of bulk SbSI (Antimony Sulfide Iodide 2000), respectively.

Absorption edge visible on DRS characteristic for cellulose/SbSI composite (Fig. 2a) is adequate to be observed for SbSI nanowires. Using the method presented in Nowak et al. (2009a), the energy gap of SbSI in the composite was determined. Value of this energy gap $\mathrm{E}_{\mathrm{g}}=1.835(23) \mathrm{eV}$ is in good agreement with results presented previously for SbSI (Nowak et al. 2008). For wavelengths higher than $700 \mathrm{~nm}$, the presence of cellulose fibers causes monotonous decrease of cellulose/SbSI reflectance coefficient.

Figures $4 a$, b show regularly dispersed SbSI nanowires among cellulose fibers connected all 
together. SbSI nanowires constitute $23 \%$ of composite mass. According to Nan and Jia (2015), the fabricated cellulose/SbSI NC can be qualified as so-called 0-3type nanocomposite with SbSI nanowires randomly dispersed in a cellulose matrix. Composite of cellulose fibers and SbSI nanowires is much more elastic than bulk SbSI samples (measurements of the elasticity are in progress). Therefore, the cellulose/SbSI composite is much more suitable for fabrication of piezoelectric generators than SbSI crystals alone.

Figure 5a presents sinusoidal open circuit voltage of cellulose/SbSI nanogenerator for sound excitation. The signal peak is $\mathrm{U}_{\mathrm{OC} \text { (peak) }}=42.0(12) \mathrm{mV}$, which gives RMS voltage $\mathrm{U}_{\mathrm{OC}(\mathrm{RMS})}=29.7$ (9) $\mathrm{mV}$ for $\mathrm{L}_{\mathrm{p}}=90 \mathrm{~dB}$ sound pressure level. The ratio of cellulose/SbSI NG voltage response to sound pressure level increases with the frequency of acoustical signal (Fig. 5b), attains maximum for $\mathrm{f}_{\mathrm{REZ}}=175 \mathrm{~Hz}$, and then decreases. The $f_{\text {REZ }}$ is resonance frequency

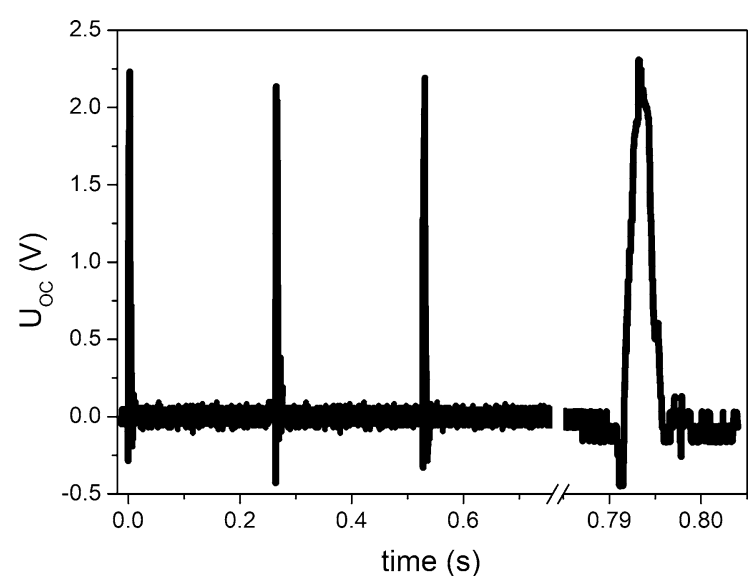

Fig. 7 Transient characteristic of open-circuit voltage generated in cellulose/SbSI nanogenerator under shock pressure excitation depending on the mass of the sample and its stiffness coefficient. The latter is influenced by the flexibility and relaxation delay of cellulose fibers responsible for elastic properties of NG. This is a common phenomenon for paper NGs (Nan and Jia 2015).

Figure 6a shows output voltage $\mathrm{U}_{\mathrm{L}(\mathrm{RMS})}$ of cellulose/SbSI nanogenerator for sinusoidal sound wave excitation ( $\mathrm{f}=175 \mathrm{~Hz}, \mathrm{~L}_{\mathrm{p}}=90 \mathrm{~dB}$ ) as a function of current density calculated for electrode area. This characteristic is typical for source of electromotive force. The RMS power density calculated for volume $\mathrm{V}$ of cellulose/SbSI NG (Fig. 6b) was determined by measuring the RMS voltage $\mathrm{U}_{\mathrm{L}(\mathrm{RMS})}$ for various load resistances $R_{L}$ (corrected for the Princeton EG\&G 5110 input impedance of $100 \mathrm{M} \Omega$ ). The presented characteristic was least square fitted (Fig. 6b) with theoretical dependence:

$P_{L}\left(R_{L}\right)=\frac{R_{L} \cdot E^{2}}{V\left(Z_{S}+R_{L}\right)^{2}}$,

where $\mathrm{E}=30.0(55) \mathrm{mV}$ is electromotive force and $\mathrm{Z}_{\mathrm{S}}=2.90(11) \mathrm{M} \Omega$ is internal source impedance. The maximum power density output of cellulose/SbSI nanogenerator equals $41.5 \mathrm{nW} / \mathrm{cm}^{3}$ for load resistance comparable with source impedance.

Figure 7 represents transient characteristic of opencircuit voltage generated in cellulose/SbSI nanogenerator under shock pressure excitation (the last peak is shown for enlarged time scale). When the air gun was turned on, the voltage increased sharply with time, passed through a maximum, and decreased to nearzero value. The recovery process was slower than rapid initial rise of open-circuit voltage (Fig. 7). The rise-time of the electromotive force is related to the shock front propagation time through the ferroelectric sample thickness (Shkuratov et al. 2010).

Table 1 Comparison of functional parameters of different piezoelectric nanogenerators based on cellulose fibers

\begin{tabular}{|c|c|c|c|c|c|}
\hline \multirow{2}{*}{$\begin{array}{l}\text { Material } \\
\text { Exciting force }\end{array}$} & \multicolumn{2}{|c|}{ Cellulose/SbSI } & \multirow{2}{*}{$\begin{array}{l}\text { Bacterial cellulose } / \mathrm{BaTiO}_{3} \\
\text { Bending }\end{array}$} & \multirow{2}{*}{$\begin{array}{l}\text { Fibers/ZnO/paper } \\
\text { Pressing }\end{array}$} & \multirow{2}{*}{$\begin{array}{l}\text { Cellulose/ZnO } \\
\text { Ultrasonic waves }\end{array}$} \\
\hline & Sound wave & Pulse pressure & & & \\
\hline $\mathrm{U}_{\mathrm{OC}}(\mathrm{V})$ & 0.024 & 2.5 & 14 & 0.018 & \\
\hline $\mathrm{I}_{\mathrm{SC}}\left(\mathrm{nA} / \mathrm{cm}^{2}\right)$ & 20 & & 190 & 90 & 700 \\
\hline $\mathrm{P}_{\mathrm{S}}\left(\mathrm{nW} / \mathrm{cm}^{2}\right)$ & 0.21 & & 640 & 5.1 & \\
\hline Remarks & $175 \mathrm{~Hz}$ & 30 bar & Polarized sample & & $40 \mathrm{kHz}$ \\
\hline References & This article & & Zhang et al. (2016) & Liao et al. (2014) & Kumar et al. (2011) \\
\hline
\end{tabular}


Values of functional parameters (generated voltage, current, and power) of cellulose/SbSI nanogenerators presented in this article are hard to compare to data reported for piezoelectric papers (Kumar et al. 2011; Liao et al. 2014; Zhang et al. 2016). Different researchers applied various excitation methods (i.e., bending, pressing, and ultrasonic waves). In addition, the power of used excitation is unknown. But, one can recognize (Table 1) that parameters of nanogenerators made of novel cellulose/SbSI paper are comparable with those of other devices. Although, various materials for electrodes as well as their different geometries should be taken into serious consideration to improve functional parameters of cellulose/SbSI nanogenerators.

\section{Conclusions}

Piezoelectric paper based on antimony sulfoiodide (SbSI) nanowires was presented for the first time. It is useful to construct nanogenerators for mechanical to electrical energy conversion. A simple device containing one pair of electrodes in sandwich configuration allows to generate open-circuit voltage of $24 \mathrm{mV}$ and $2.5 \mathrm{~V}$ under sound excitation $(\mathrm{f}=175 \mathrm{~Hz}$, $\mathrm{L}_{\mathrm{p}}=90 \mathrm{~dB}$ ) and shock pressure (30 bar, $\left.144 \mathrm{~m} / \mathrm{s}\right)$, respectively. Maximum output power of $0.21 \mathrm{nW} / \mathrm{cm}^{2}$ was registered for $0.05-\mathrm{mm}$-thick sheet of cellulose/ SbSI.

Fabrication of cellulose/SbSI nanogenerators is low cost, simple, and effective. Functional parameters of these cellulose/SbSI nanogenerators should be improved in the future for optimized electrode configuration and device connection. Bending and vibration tests of these nanogenerators will be performed.

Cellulose/SbSI piezoelectric paper may also be useful to construct gas nanosensors and actuators.

Acknowledgments This paper was partially supported by the Institute of Physics-Center for Science and Education, Silesian University of Technology and financial support for young scientists (BK/RIF/2017, 14/990/RGH17/0095, BKM-520/RIF/ 2017).

Open Access This article is distributed under the terms of the Creative Commons Attribution 4.0 International License (http:// creativecommons.org/licenses/by/4.0/), which permits unrestricted use, distribution, and reproduction in any medium, provided you give appropriate credit to the original author(s) and the source, provide a link to the Creative Commons license, and indicate if changes were made.

\section{References}

Antimony Sulfide Iodide (2000) JCPDS-International Centre for Diffraction Data, PCPDFWIN v.2.1, card file no. 74-0149

Chen X, Xu S, Yao N, Shi Y (2010) Nanogenerator for mechanical energy harvesting using PZT nanofibers. Nano Lett 10:2133-2137

Chen J, Zhu G, Yang W, Jing Q, Bai P, Yang Y, Hou TC, Wang ZL (2013) Harmonic-resonator-based triboelectric nanogenerator as a sustainable power source and a self-powered active vibration sensor. Adv Mater 25:6094-6099

Fan FR, Lin L, Zhu G, Wu W, Zhang R, Wang ZL (2012) Transparent triboelectric nanogenerators and self-powered pressure sensors based on micropatterned plastic films. Nano Lett 12:3109-3114

Fang H, Li Q, He W, Li J, Xue Q, Xu C, Zhang L, Ren T, Dong G, Chan HLW, Dai J, Yan Q (2015) A high performance triboelectric nanogenerator for self-powered non-volatile ferroelectric transistor memory. Nanoscale 7:17306-17311

Gao T, Liao J, Wang J, Qiu Y, Yang Q, Zhang M, Zhao Y, Qin L, Xue L, Xiong Z, Chen L, Wang QM (2015) Highly oriented $\mathrm{BaTiO}_{3}$ film self-assembled using an interfacial strategy and its application as a flexible piezoelectric generator for wind energy harvesting. J Mater Chem A 3:9965-9971

Grekov AA, Danilova SP, Zaks PL, Kulieva VV, Rubanov LA, Syrkin LN, Chekhunova NP, El'gard AM (1973) Piezoelectric elements made from antimony sulphoiodide crystals. Akust Z 19:622-623

Gullapalli H, Vemuru VSM, Kumar A, Botello-Mendez A, Vajtai R, Terrones M, Nagarajaiah S, Ajayan PM (2010) Flexible piezoelectric $\mathrm{ZnO}$-paper nanocomposite strain sensor. Small 6:1641-1646

Hamano K, Nakamura T, Ishibashi Y, Ooyane T (1965) Piezoelectric property of SbSI single crystal. J Phys Soc Jpn 20:1886-1888

Hua Y, Wang ZL (2015) Recent progress in piezoelectric nanogenerators as a sustainable power source in selfpowered systems and active sensors. Nano Energy 14:3-14

Kumar A, Gullapalli H, Balakrishnan K, Botello-Mendez A, Vajtai R, Terrones M (2011) Flexible ZnO-cellulose nanocomposite for multisource energy conversion. Small 7:2173-2178

Lee S, Hinchet R, Lee Y, Yang Y, Lin ZH, Ardila G, Montès L, Mouis M, Wang ZL (2014) Ultrathin nanogenerators as self-powered/active skin sensors for tracking eye ball motion. Adv Funct Mater 24(8):1163-1168

Liao Q, Zhang Z, Zhang X, Mohr M, Zhang Y, Fecht H-J (2014) Flexible piezoelectric nanogenerators based on fiber/ZnO nanowires/paper hybrid structure for energy harvesting. Nano Res 7:917-928

Mahadeva SK, Walus K, Stoeber B (2014) Piezoelectric paper fabricated via nanostructured barium titanate functionalization of wood cellulose fibers. ACS Appl Mater Interfaces 6:7547-7553 
Mistewicz K, Nowak M, Stróż D, Paszkiewicz R (2016) SbSI nanowires for ferroelectric generators operating under shock pressure. Mater Lett 180:15-18

Nan CW, Jia Q (2015) Obtaining ultimate functionalities in nanocomposites: design, control, and fabrication. MRS Bull 40:719-724

Nitsche R, Roetschi H, Wild P (1964) New ferroelectric V-VIVII compounds of the SbSI type. Appl Phys Lett 4:210-211

Nowak M, Szperlich P, Bober Ł, Szala J, Moskal G, Stróż D (2008) Sonochemical preparation of SbSI gel. Ultrason Sonochem 15:709-716

Nowak M, Kauch B, Szperlich P (2009a) Determination of energy band gap of nanocrystalline SbSI using diffuse reflectance spectroscopy. Rev Sci Inst 80(046107):1-3

Nowak M, Mroczek P, Duka P, Kidawa A, Szperlich P, Grabowski A, Szala J, Moskal G (2009b) Using of textured polycrystalline SbSI in actuators. Sensor Actuat A Phys 150:251-256

Nowak M, Nowrot A, Szperlich P, Jesionek M, Kępińska M, Starczewska A, Mistewicz K, Stróż D, Szala J, Rzychoń T, Talik E, Wrzalik R (2014) Fabrication and characterization of SbSI gel for humidity sensors. Sens Actuat A Phys 210:119-130

Nowak M, Tański T, Szperlich P, Matysiak W, Kępińska M, Stróż D, Bober Ł, Toroń B (2017) Using of sonochemically prepared SbSI for electrospun nanofibers. Ultrason Sonochem 38:544-552

Poulin-Vittrant G, Oshman C, Opoku C, Dahiya AS, Camara N, Alquier D, Tran Huu Hue LP, Lethiecq M (2015) Fabrication and characterization of $\mathrm{ZnO}$ nanowire-based piezoelectric nanogenerators for low frequency mechanical energy harvesting. Phys Proc 70:909-913

Shkuratov SI, Talantsev EF, Baird J (2010) Application of piezoelectric ceramics in pulsed power technology and engineering. In: Suaste-Gomez E (ed) Piezoelectric ceramics. Sciyo, Rijeka, pp 269-294

Szperlich P, Nowak M, Bober Ł, Szala J, Stróż D (2009) Ferroelectric properties of ultrasonochemically prepared SbSI ethanogel. Ultrason Sonochem 16:398-401

Wang X (2012) Piezoelectric nanogenerators-harvesting ambient mechanical energy at nanometer scale. Nano Energy $1: 13-24$

Wang ZL, Song J (2006) Piezoelectric nanogenerators based on zinc oxide nanowire arrays. Science 312:242-246

Wang X, Song J, Liu J, Wang ZL (2007) Direct-current nanogenerator driven by ultrasonic waves. Science 316:102-105

Yang R, Qin Y, Li C, Zhu G, Wang ZL (2009) Converting biomechanical energy into electricity by a muscle-movement-driven nanogenerator. Nano Lett 9:1201-1205

Zadorozhnaya LA, Lyakhovitskaya VA, Belyaev LM (1973) Morphology of the domain structure of SbSI crystals. Kristallografiya 18:579-583

Zhan Z, Liao Q, Yan X, Wang ZL, Wang W, Sun X, Lin P, Huang Y, Zhang Y (2014) Functional nanogenerators as vibration sensors enhanced by piezotronic effects. Nano Res 7:190-198

Zhang G, Liao Q, Zhang Z, Liang Q, Zhao Y, Zheng X, Zhang Y (2016) Novel piezoelectric paper based flexible nanogenerators composed of $\mathrm{BaTiO}_{3}$ nanoparticles and bacterial cellulose. Adv Sci 3(1500257):1-7 